\title{
VISUALISATION RESEARCH INTO FUEL SPRAY PROPAGATION
}

The results of research into a new construction of a diesel engine multi-hole injector are presented. The injector needle (RSN injector) performs a rotary/swinging movement. During the fuel injection the needle changes the area of atomizing orifices. This design changes the shape of atomized fuel sprays and has impact on their properties. The range of the spray front, the top angle of the spray and the area of the spray projection in a plane perpendicular to the injector axis were analyzed.

\section{Introduction}

Numerous papers indicate that the present classical systems of fuel injection directly into the combustion chamber, in the most economical directly injected Diesel engines, have reached the limit of development from an ecological point of view. In order to keep the emission of toxic components of exhaust gases within the ranges defined by both the EURO III standard and by the projected EURO IV standard, various modifications to the combustion system become necessary. Initially the fuel injection phase and the distribution of injected material within the combustion chamber should be considered $[1,2,3,6,10]$. It is known that injection through a conventional multi-hole nozzle (classical injector), in combination with induced swirl in the air in the chamber fails to ensure that particulates and oxides of nitrogen are not formed. These toxic components are among the most difficult to be subsequently removed from exhaust gases. For a significant advance in this area the mechanism by which the combustible mixture is formed must be radically altered. The overall process involves the following stages: fuel injection/spray formation, evaporation of fuel droplets, admixture with air, reactions immediately before combustion, the combustion process itself.

A fuel spray with a different micro and macro structure might have an important effect on these processes. In order to achieve this it is necessary to use a different type of injector - a new type of construction and modus operation [9]. A design for such a device forms the subject of the paper $[4,5,7,8]$. The special feature of the spray-nozzle of this injector is the variability of the fuel-spraying holes during injection. The variability of the cross-sections of these holes is achieved by a rotary/swinging movement of a needle (RSN injector). The results of investigations described below show that a spray generated by this design of injector has macro-structural parameters that differ from those of a classical/traditional injector.

\section{Results and discussion}

The parameters of macrostructure of the stream of sprayed fuel were determined on the basis of measurements carried out using specially constructed equipment, which enabled both a direct observation of the development of the spray during the fuel injection to a chamber of fixed volume $[4,7,8]$ and the measurement of the fuel distribution within the spray of droplets.

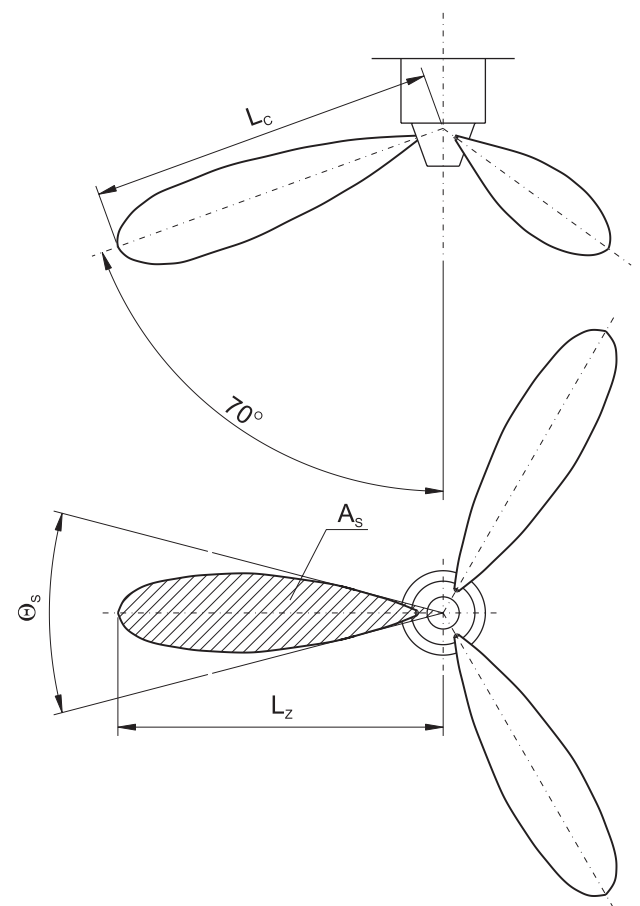

Fig. 1. The method of determining the values of parameters of the fuel spray

\footnotetext{
${ }^{*}$ Hubert Kuszewski ${ }^{1}$, Kazimierz Lejda ${ }^{1}$, Zygmunt Szlachta ${ }^{2}$

${ }^{1}$ Rzeszow University of Technology, Faculty of Mechanical Engineering and Aeronautics, Department of Automotive Vehicles and Internal Combustion Engines 8 Powstańców Warszawy Ave., 35-959 Rzeszow, Poland, E-mail: hkuszews@prz.rzeszow.pl (favoured contact), klejda@prz.rzeszow.pl

${ }^{2}$ Cracow University of Technology, Faculty of Mechanical Engineering, Institute of Automotive Vehicle and Internal Combustion Engines, Division of Diesel Engines, 37 Jana Pawła II Ave., 31-864 Cracow, Poland, E-mail: z.szlachta@usk.pk.edu.pl
} 
The visual studies enabled the following to be analyzed: the range of the spray front $-L_{c}$, the top angle of the spray $-\theta_{s}$ and the area of the spray projection in a plane perpendicular to the injector axis $-A_{s}$. The last criterion of the spray macrostructure estimation was introduced because of the irregular shape of the spray generated by the RSN injector. The method of determination of the values of the analyzed parameters of the spray of injected fuel is depicted in Fig. 1.

A classical injector with a D1LMK 140/M2 pattern sprayer and the new RSN injector denoted "B" were compared. Both sprayers had three outlet holes, the diameter of the holes in the

Basic parameters of practical spray nozzles in visualization research

Tab. 1

\begin{tabular}{|l|c|c|c|c|c|c|c|}
\hline Symbol & $i_{r}$ & $l_{r} / d_{k}$ & $d_{i}[\mathrm{~mm}]$ & $d_{k}[\mathrm{~mm}]$ & $h_{i \max }[\mathrm{mm}]$ & $h_{\max }[\mathrm{mm}]$ & $\alpha_{i \max }\left[{ }^{\circ}\right]$ \\
\hline „B" (with rot.-swing. needle movement) & 3 & - & 0.40 & 0.60 & - & 1.09 & 20 \\
\hline
\end{tabular}

Symbols: $i_{r}$ - number of spraying holes, $l_{r} / d_{k}$ - relation length of the spraying hole to its diameter (in spray nozzle with a rotary-swinging needle the movement section of the spraying hole changes within duration of injection because it is not possible to exactly define this parameter), $d_{i}$ - diameter of the spraying hole in a needle (only an injector with rotary-swinging needle movement), $d_{k}$ - diameter of the spraying hole in a spray nozzle holder, $h_{\text {imax }}$ - maximum needle stroke (only a classical injector), $h_{\text {tmax }}$ - maximum piston stroke (only an injector with rotary-swinging needle movement), $\alpha_{\text {imax }}$ - maximum angle of the needle rotation (only an injector with rotary-swinging needle movement)

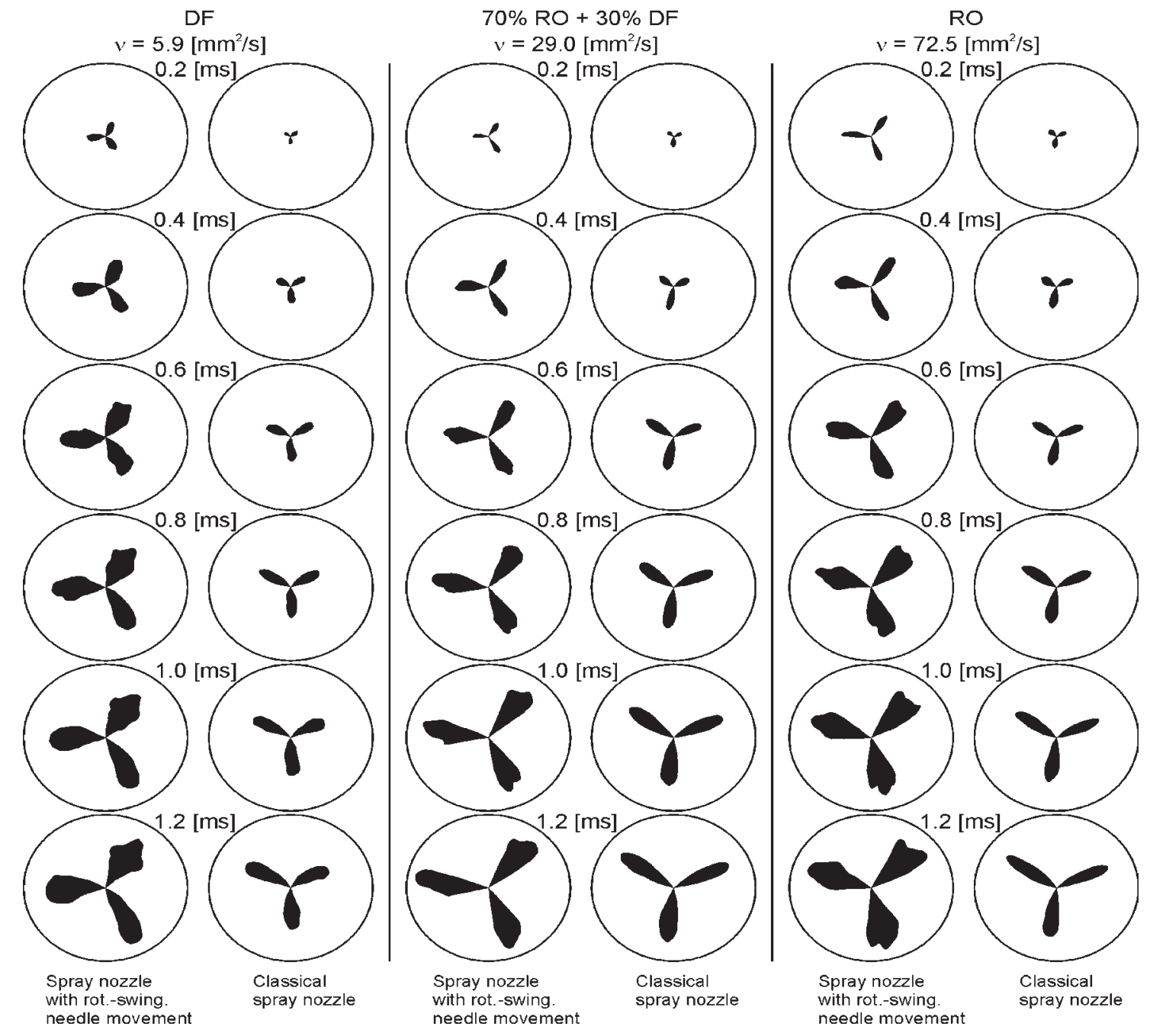

Fig. 2. Pictures of fuel sprays propagation obtained from a three-hole spray nozzle with rotary-swinging needle movement and classical $\left(p_{o}=170\right.$ [bar], $p_{b}=20$ [bar], $q=130\left[\mathrm{~mm}^{3} /\right.$ injection], $n_{p}=600$ [rpm], fuel: $D F, 70 \%$ RO $\left.+30 \% \mathrm{DF}, \mathrm{RO}\right)$ 
classical injector body and the RSN type being equal. The basic parameters of the investigated spray nozzles (classical and "B") are shown in table 1.

In Fig. 2. the example pictures of the fuel sprays propagation achieved in visualization research were shown, which created a basis for their quantitative analysis. The figures illustrate injection of diesel fuel (DF), rape oil (RO) and mixture of these fuels to visualization chambers in identical conditions. From the figures it can be clearly seen that fuel spray generated by a spray nozzle with rotary-swinging needle movement is formed in a different way than fuel spray formed by a classical spray nozzle, which causes differences in the values of an estimation parameters of the macrostructure of fuel spray. In particular it shows that fuel spray formed by a spray nozzle with rotary-swinging needle movement has an irregular form and its surface (in the view on perpendicular surface to the axis of spray nozzle), cone angle and tip penetration in comparison to the classical spray nozzle are mostly evidently larger.

\subsection{The range of the spray front}

In both injectors the following values were set, being the same for each type: line pressure at the opening of the sprayer $p_{o}=170$ [bar], fuel dose $q=130\left[\mathrm{~mm}^{3} /\right.$ injection] and rotary velocity of the camshaft of the injection pump $n_{p}=600$ [rpm]. Fuels of different viscosity (diesel fuel (DF), rape oil (RO), 70/30 RO/DF mixture) were injected into the observation chamber, filled with nitrogen at pressures of 15,20 , and 25 bars.

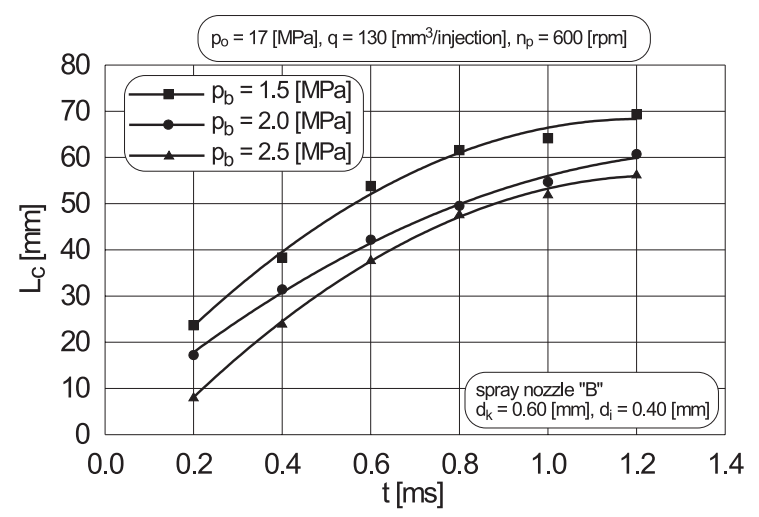

Fig. 3. The range of the diesel fuel spray front formed by the RSN type, at various background pressures in the observation chamber

The range of the spray front for diesel fuel, formed by the RSN sprayer under various values of the background pressure in the observation chamber is presented in Fig. 3. It can be seen that an increase of nitrogen pressure in the observation chamber caused - as was expected - a reduction in the range of the spray front. This phenomenon is characteristic of classical sprayers, and may be ascribed to the effect of the aerodynamic resistance on droplets of variable size. An increase in the background pressure (gas density) causes an increase in aerodynamic resistance, and a reduced dyna-

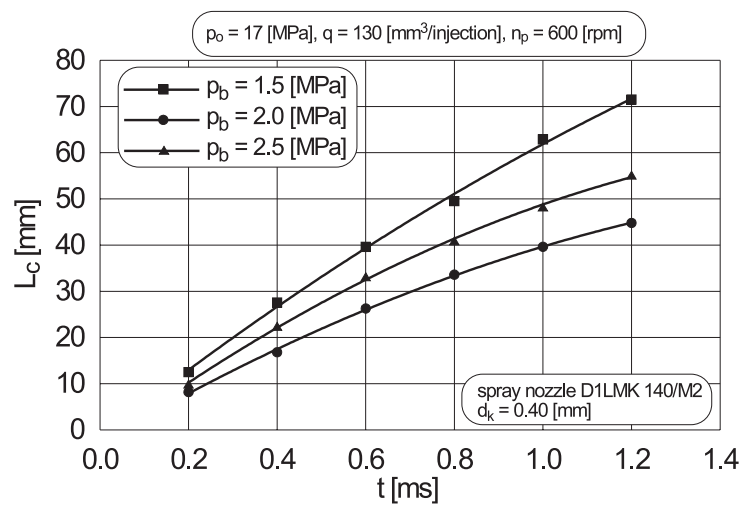

Fig. 4. The range of the diesel fuel spray front formed by the classical injector, at various background pressures in the observation chamber

mic pressure of the gas into which the injection is made, creating adverse conditions for the disintegration of secondary droplets. Therefore, larger droplets with greater penetrative capability are formed (obviously a larger droplet has greater kinetic energy and will, therefore, travel further).

The greatest range of the front of the diesel fuel spray formed by both the classical injector (Fig. 4) and the RSN injector was observed at $p_{b}=15$ [bar]. However, at $p_{b}=20$ [bar] the range of the front was less than at $p_{b}=25$ [bar]. Most probably this was because of the analyzed (single) injection, at $p_{b}=25$ [bar] the initial velocity of fuel at the sprayer outlet was higher than that at $p_{b}=20$ [bar]. This was caused by the greater difference between the line pressure and that in the observation chamber. Therefore, the greater kinetic energy of the spray at $p_{b}=25$ [bar] had a stronger influence on the movement of the front of the spray than the enhanced aerodynamic resistance of the environment. A comparison of Figs. 3 and 4 shows that generally the range of the front of the spray generated by the RSN sprayer is greater than that of the classical injector.

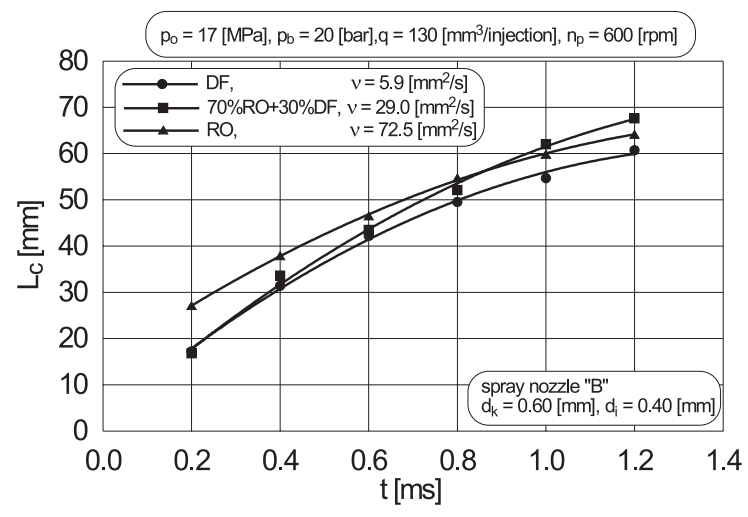

Fig. 5. The range of the front of the spray, formed by the RSN injector for fuels differing in physical properties

As it could be expected, the use of fuels of considerably greater viscosity affected both types of injectors by considerably increas- 
ing the injection pressures. This was caused by a reduction in the value of the index of fuel outflow from the sprayer holes. These changes were the main contributor to the increase of the spray front range for fuels of increased viscosity $\left(R O-\nu=72.5\left[\mathrm{~mm}^{2} / \mathrm{s}\right]\right.$ $\left.70 / 30 R O / D F-\nu=29.0\left[\mathrm{~mm}^{2} / \mathrm{s}\right]\right)$, in relation to diesel fuel $\left(D F-\nu=5.9\left[\mathrm{~mm}^{2} / \mathrm{s}\right]\right)-$ see Figs. 5 and 6 . An additional reason for the increase in range of the spray front when using higher viscosity fuels, observed for both types of injectors, was probably the increase in droplet size, due to the conditions conducive to their disintegration being worse

From a comparison of Figs. 5 and 6 it may be seen that, as in the case of diesel fuel, the spray-range of other fuels was greater for the RSN injector over the whole time of spray development.

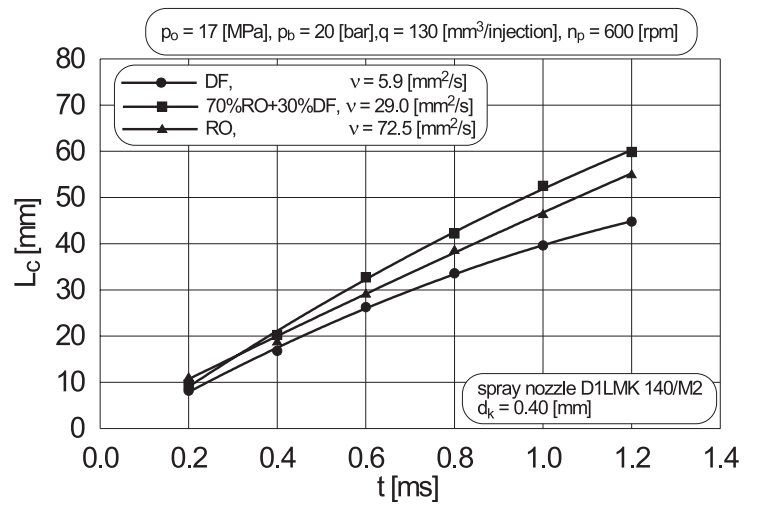

Fig. 6. The range of the front of the spray, formed by the classical injector for fuels differing in physical properties

\subsection{The apex angle and surface area of the spray}

In Fig. 7 it may be seen that in the case of the RSN sprayer a change in background pressure did not significantly affect the values of the apex angles of the spray over the whole time of its development. However, the spray surface area varied, the greatest area being observed for $p_{b}=15$ [bar], i.e. at the background pressure at which the range of the spray was greatest.

Conversely, in the case of the classical injector the effect of $\mathrm{pb}$ on the apex angle $\theta_{s}$ was more visible - $c p$. Fig. 8. As it could be expected, the largest apex angles occurred at maximum background pressure. The values of the apex angles of the spray diminished during its development, i.e. the penetration of the spray in a direction perpendicular to its axis was reduced. For mixing this is a negative effect. It may be only partly compensated by the fact that the spray surface area increases with its development. The smallest surface area of the spray was recorded at the intermediate background pressure, $p_{b}=20$ [bar], i.e. for a value corresponding to the shortest range of the spray front.

From a comparison of Figs. 7 and 8 it will be seen that the values As achieved by the RSN injector were greater than for the classical injector. It may additionally indicate the better properties of the spray from the RSN injector, due to better air/fuel mixing processes.

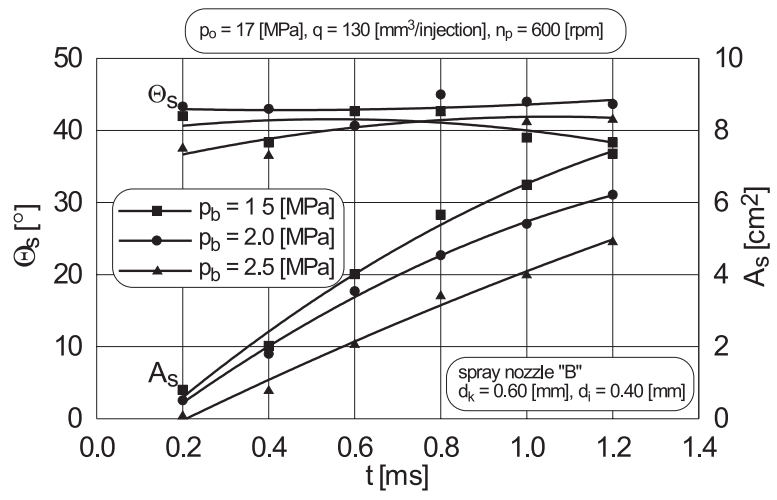

Fig. 7. The apex angle and surface area of the spray formed by the RSN type at various background pressures levels

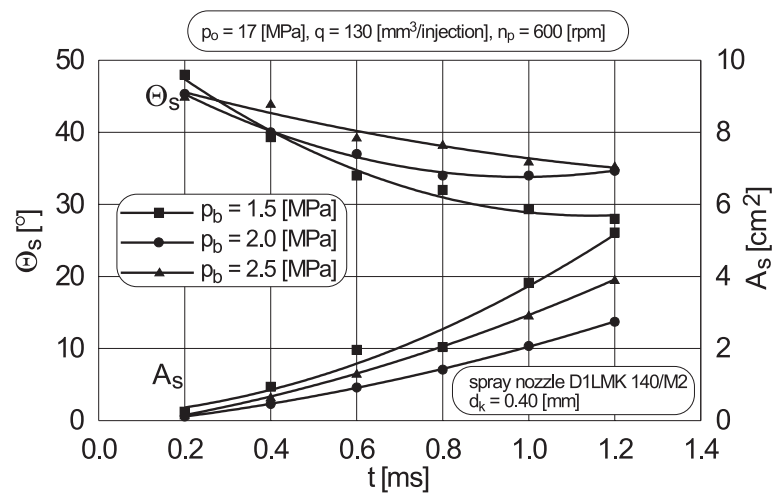

Fig. 8. The apex angle and surface area of the spray formed by the classical injector at various background pressures levels

\section{Conclusions}

The results of the investigations show that the spray of fuel formed using an RSN-type in a different way than that generated by a classical injector. In particular, the parameters analyzed, i.e. the range of the spray-front, the apex angle of the spray and its surface area, reach greater values for a spray formed by the new RSN type of sprayer. It may positively affect the ecological impact and the performance of engines fitted with injectors of this type.

The variation of the conditions of injection (change of the pressure of the gaseous medium into which fuel is injected, change due to use of fuels of differing viscosity) affects the macrostructure of sprays, generated by each type of injector differently. The best example may be the variance in the apex angle of the spray during spraying RO.

In the case of the classical injector it was found that this angle diminished as the spray developed, while in the case of the RSN injector the opposite tendency was observed. 


\section{Nomenclature}

\begin{tabular}{|c|c|c|}
\hline Quantity & Unit & Specification \\
\hline$A_{s}$ & {$\left[\mathrm{~cm}^{2}\right]$} & surface of view of fuel spray on perpendicular plane to spray nozzle axis \\
\hline$L_{c}$ & {$[\mathrm{~mm}]$} & real tip penetration of fuel spray \\
\hline$L_{z}$ & {$[\mathrm{~mm}]$} & measured tip penetration of fuel spray \\
\hline$\Theta_{s}$ & {$\left[{ }^{\circ}\right]$} & cone angle of fuel spray \\
\hline$d_{k}$ & {$[\mathrm{~mm}]$} & outlet hole diameter in a needle \\
\hline$d_{i}$ & {$[\mathrm{~mm}]$} & outlet hole diameter in a spray nozzle body \\
\hline$Q$ & {$\left[\mathrm{~mm}^{3} /\right.$ injection] } & fuel dose \\
\hline$T$ & {$[\mathrm{~ms}]$} & time \\
\hline$n_{p}$ & {$[\mathrm{rpm}]$} & rotational speed of the injection pump camshaft \\
\hline$p_{o}$ & [bar] & static opening pressure of injector \\
\hline$p_{b}$ & [bar] & ambient gas pressure \\
\hline$p_{\text {wmax }}$ & [bar] & maximum fuel injection pressure \\
\hline$p_{\text {wav }}$ & [bar] & average fuel injection pressure \\
\hline$\nu$ & {$\left[\mathrm{mm}^{2} / \mathrm{s}\right]$} & kinematic viscosity of fuel \\
\hline$D F$ & - & diesel fuel \\
\hline RO & - & rape oil \\
\hline
\end{tabular}

\section{References}

[1] DÜRNHOLZ, M., KRÜGER. M.: Has diesel engine a future as drive of the car? (in German), 6. Aachener Kolloquium Fahrzeug und Motorentechnik, Akwizgran 1997.

[2] FRÄNKLE, G.: Limits of exhaust gas for light duty trucks - Diesel engines (in German), Symposium Dieselmotorentechnik 98, Technische Akademie Esslingen Esslingen - Ostfildern 1997.

[3] KOLLMANN, K., BARGENDE, M.: DI diesel engine and DI spark ignition engine - Where the development of motorization is going to? (in German, Symposium Dieselmotorentechnik 98, Technische Akademie Esslingen Esslingen - Ostfildern 1997.

[4] KUSZEWSKI, H.: The influence of changing outlet section of injector with a rotary needle on diesel fuel spraying. (in Polish), Ph.D. Dissertation, Cracow University of Technology, Cracow 2002.

[5] KUSZEWSKI, H., LEJDA, K., SZLACHTA, Z.: The comparison of fuel sprays formed by classic injector and with rotary-swinging needle movement on the basis of the radial distribution of fuel. (in Polish) "Motor Transport", Scientific Quarterly of Institute of Motor Transport, Warsaw 2003.

[6] PEAKE, S.: Vehicle and fuel - Challenges beyond 2000, Automotive Publishing, London 1997.

[7] SOWA, K., SZLACHTA, Z., ZABŁOCKI, M., KUSZEWSKI, H.: The test of new environmentally friendly combustion system for high-speed diesel engine with a spray nozzle with changing section of spraying fuel orifices. (in Polish), Rep. 9 T12 D 016 16, Cracow 2001.

[8] SZLACHTA, Z., KUSZEWSKI, H.: The influence of changing outlet section of injector with a rotary needle on diesel fuel spraying. (in Polish), Rep. 5 T12D 026 22, Cracow 2002.

[9] SZYMAŃSKI, J., ZABŁOCKI, M.: The injector for combustion engine. (in Polish), Patent Application in Patent Department R.P, No: P-294889, 11. 06. 1992.

[10] ZABŁOCKI, M.: Injection and burning of fuel in diesel engines. (in Polish), WKiŁ, Warsaw 1976. 